\title{
Haverá um texto neste teatro?
}

\section{Christine Zurbach}

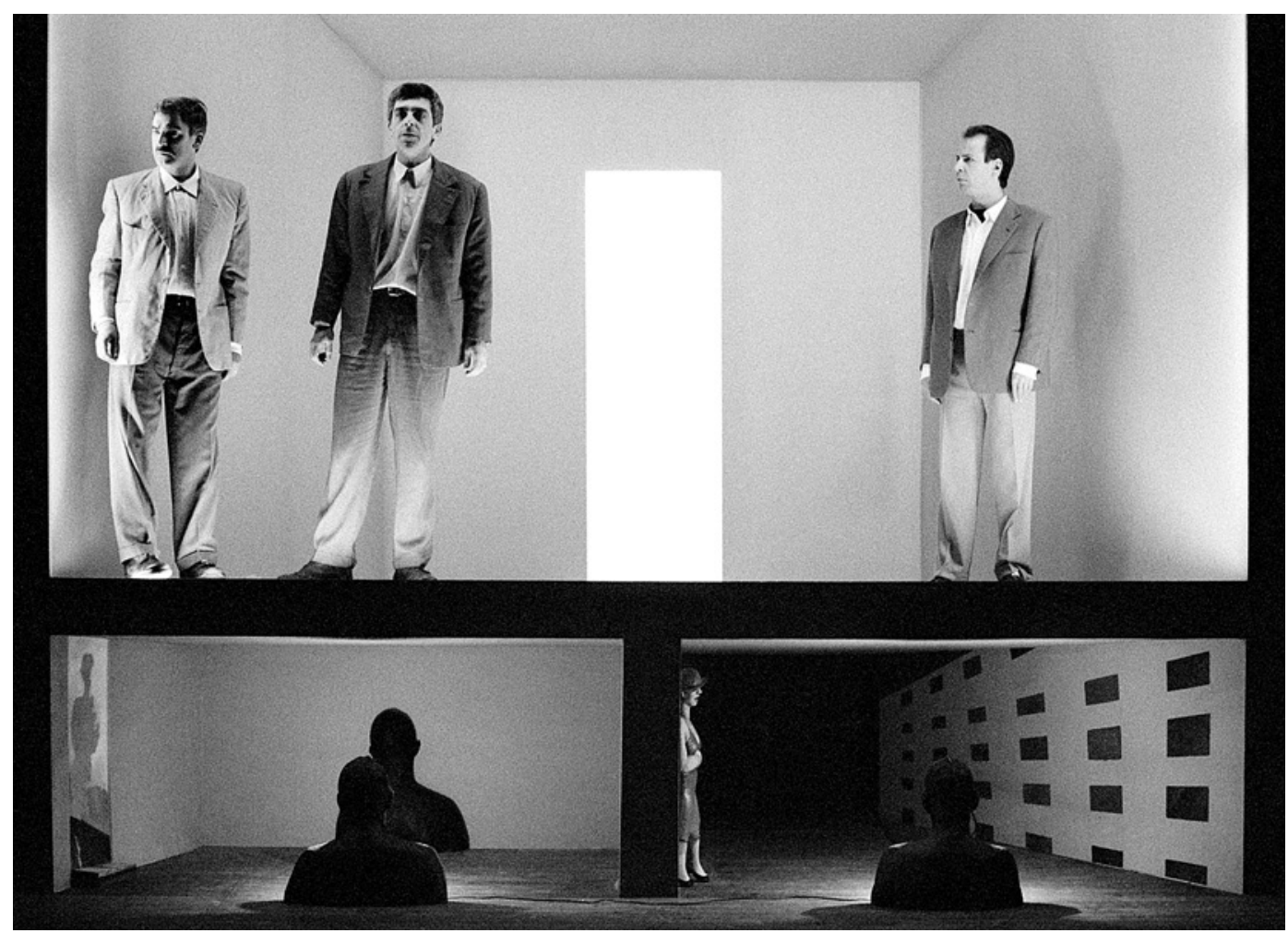

A missão,

de Heiner Müller,

enc. Luis Miguel Cintra,

Teatro da Cornucópia,

1984 (Luis Lima Barreto,

Luis Miguel Cintra

e Rogério Vieira),

fot. Paulo Cintra.

0 colóquio para o qual escrevi este texto sugeria aos participantes que se debruçassem sobre dois modelos antagónicos a propósito do lugar do aspecto dramático no teatro: "entre a des-dramatização e a re-dramatização". Sobre um tema como este, não poderei ser nem exaustiva, nem verdadeiramente original, apesar de o seu conteúdo e a sua orientação serem forçosamente representativos duma reflexão pessoal e de eu ter sido obrigada a fazer escolhas depois duma indispensável "revisão da matéria", para fins de clareza expositiva.

À primeira vista, trata-se de uma questão que se integra num debate mais vasto no seio da investigação em teatrologia que já dura há várias décadas e que, por isso mesmo, poderia ter perdido algum interesse.

A formulação é, no entanto, muito estimulante porque nos obriga a regressar, em primeiro lugar, à questão do teatro enquanto espectáculo, desdramatizado e erigido em senhor na relação com o - ou um - texto (antes, razão de ser do próprio teatro) e, em segundo lugar - ou também de forma secundária -, nesta inversão de papéis, à questão da relação que o texto poderia ainda (ou novamente) propor ao palco, portanto, ao teatro, através da sua redramatização.
Mas será o regresso de que aqui se trata um mero reflexo passadista em relação ao velho modelo textocentrista tão generalizadamente posto em causa pelos criadores? Com certeza que não, concordaremos todos seguramente. Afastado do palco, o texto regressa... Mas já não é o mesmo.

1.

Sobre este ponto, uma obra recente, publicada em 2006 e intitulada Qu'est-ce que le théâtre?, começa por uma afirmação muito clara:

0 teatro é antes de mais, um espectáculo, uma performance efémera, a prestação de actores diante de espectadores que olham, um trabalho corporal, um exercicio vocal e gestual com destinatário, a maior parte das vezes num lugar particular e num cenário particular. Para isso, não está necessariamente ligado a um texto previamente escrito e não dá necessariamente lugar à publicação dum texto. (Biet / Triau 2006: 7, trad. minha

A estes elementos de definição haverá que acrescentar outros factores que contribuíram para uma mudança da própria concepção do teatro, que já não pode hoje ser
Christine Zurbach é professora no Departamento de Artes Cénicas da

Universidade de Évora - onde lecciona nas áreas dos Estudos Teatrais e dos Estudos de Tradução - e investigadora do Centro de História de Arte e Investigação Artística (CHAIA). 


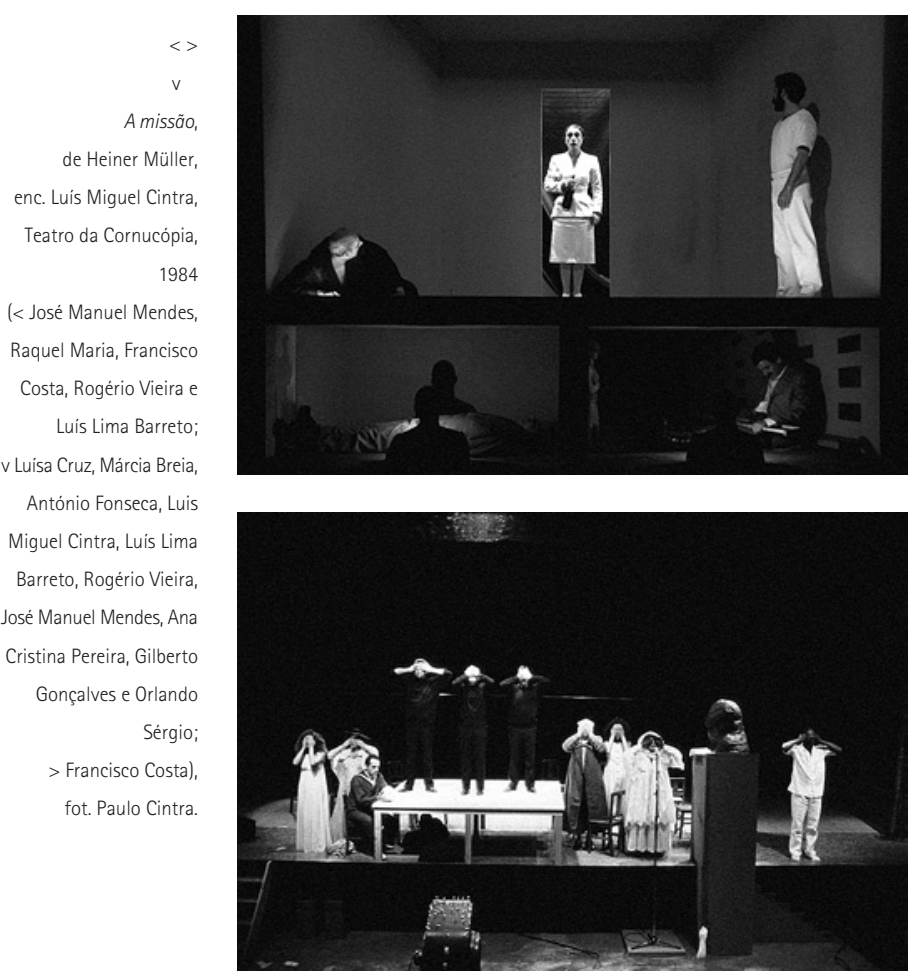

concebido fora dum quadro disciplinar cada vez mais vasto, resultado da dissolução das fronteiras entre as artes e com as artes, bem como de um novo relacionamento com os novos medias - em que o teatro de Bob Wilson foi pioneiro - a tomarem conta do palco, ao mesmo tempo que se constata uma teatralização crescente das artes, com o teatro a pôr-se a falar diferentes linguagens (Limom/ Zukowska 2010: 10).

Mas os últimos capitulos dessa obra, que abordam a teatralidade pelo ângulo, não do texto dramático, mas da encenação, e que chamam a atenção para os principais problemas associados ao abandono do texto, afirmam também numa espécie de balanço ou de fim de jornada aberto para o presente (e eventualmente para o futuro) do teatro:

0 texto, que até aqui surgia como o objecto sagrado inicial que a representação deveria "servir", agora é um elemento maior a que se regressa (o regresso do texto é uma questão importante nos últimos anos), um material como qualquer outro, o pretexto para uma performance cénica, ou está simplesmente ausente. Em vez de estar situado a montante da representação, pode portanto ser observado a jusante, como algo que o espectáculo produz ou produziu, e ver a sua materialidade textual tornar-se uma entidade semiológica histórica, estética e social: um acontecimento artístico. (Ibid.: 924, t.m.)

0 texto de teatro enquanto texto dramático - "objecto sagrado inicial" - foi assim alvo de um questionamento e de uma relativização do seu papel na criação teatral que envolvem a própria definição do texto de teatro: transformado em material, ele pode ser o produto e não já a razão de ser do espectáculo e pode (re)adquirir uma importância crescente, proporcionando à palavra uma função destacada na acção teatral como na dramaturgia exemplar de Koltès. Expulso pela porta, dir-se-ia que regressa pela janela...

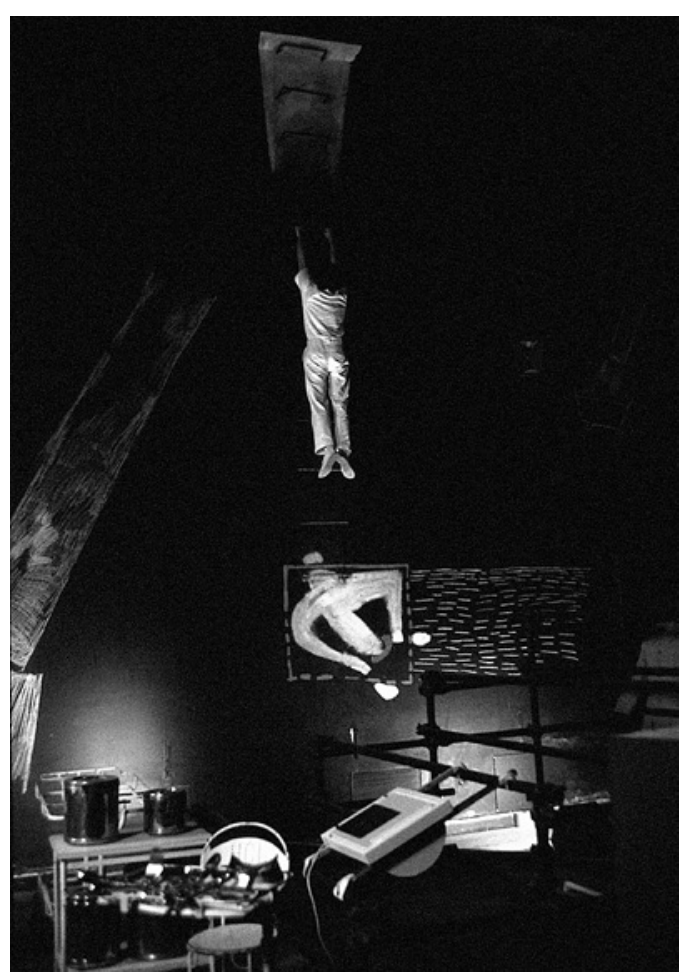

2.

Texto e dramatização são, pois, componentes interdependentes do espectáculo. Com efeito, nas definições clássicas do teatro tudo começa pelo drama quer dizer, pelo texto. Eis uma definição.

Em grego, a palavra "drama" significava acção. Assim, o drama é antes de mais "sinónimo do próprio teatro" e designa qualquer "peça escrita" para o teatro. A partir do século XVIII, a utilização da palavra restringe-se apenas aos textos sérios que se distinguem da tragédia e da comédia. Hoje, o drama designa uma peça séria mas não trágica. (Riendeau 2002: 164-165, t.m.)

Esta definição foi retirada dum dicionário literário e por essa razão, não nos surpreende. Mas a experiência da maior parte dos investigadores permite confirmar sem surpresas que o "drama" - "a peça escrita" - é entendido como sinónimo de "teatro" e está no centro da abordagem tradicional do teatro. Tradicional e "literária".

Uma exploração da bibliografia, mesmo que sumária revelaria como a realidade desta assimilação (drama $=$ teatro) se construiu no debate dos "literatos" que se interessaram pelo teatro. Esses debates condicionaram durante muito tempo a concepção do teatro propriamente dito. Também no campo da história do teatro ou da dramaturgia. Contrariamente à abundância de estudos sobre os dramaturgos - enquanto autores literários -, os trabalhos sobre a prática artística do teatro - o espectáculo de teatro, os seus agentes, o seu público e as suas instituições - escassearam durante muito tempo.

A partir dos anos setenta (do séc. XX), novas abordagens, vindas de sectores emergentes - como a história cultural, a semiologia, a antropologia, a teatrologia, etc. - vieram alterar essa realidade. Com a semiologia, a investigação pôde abordar o teatro nas suas múltiplas dimensões, verbais e não verbais. Esta viragem foi fundamental para se pensar (de forma diferente) as duas 


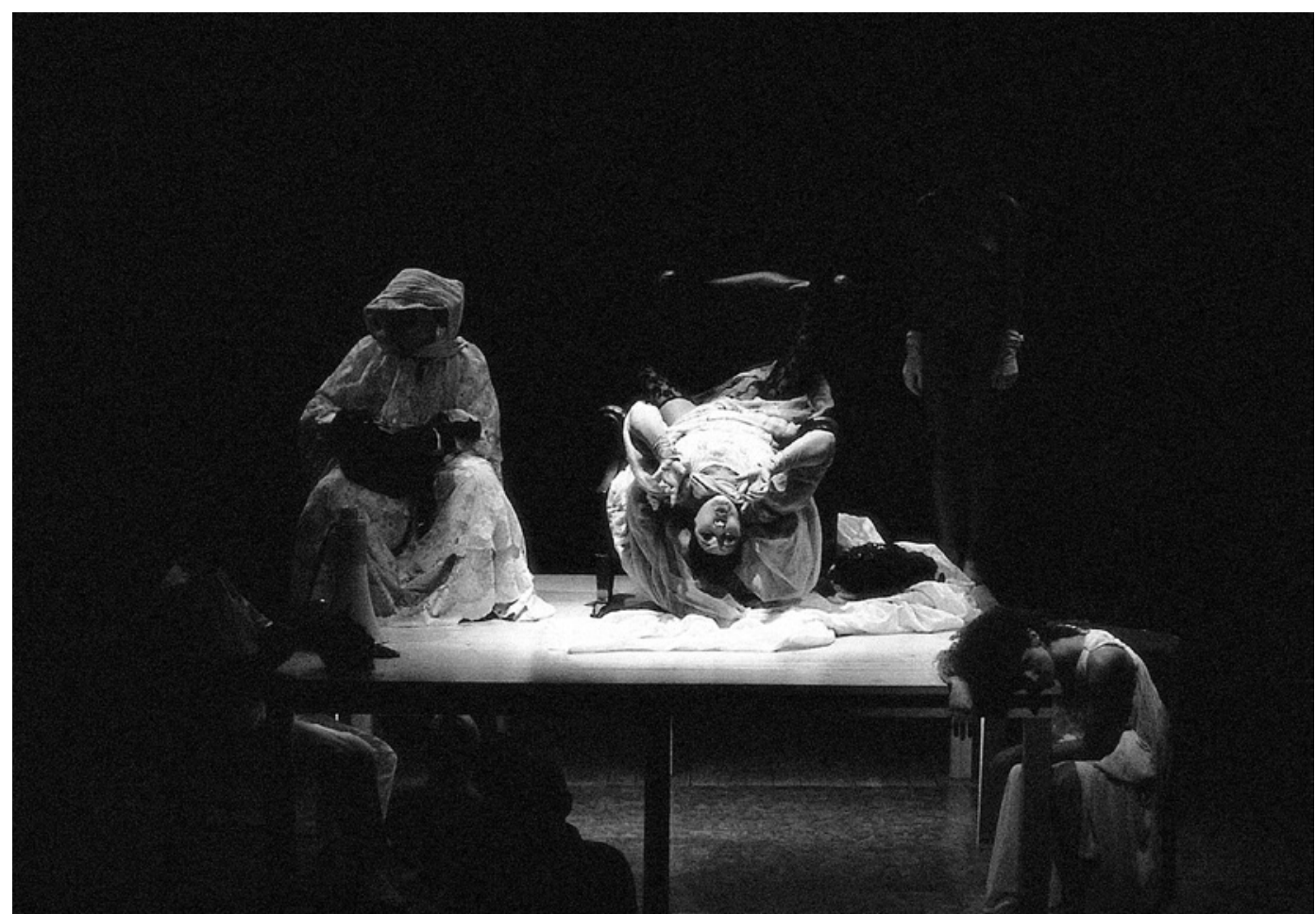

A missão,

de Heiner Müller,

enc. Luis Miguel Cintra, Teatro da Cornucópia, 1992 (Ângelo Torres, Gilberto Gonçalves, Márcia Breia, Ana Cristina Pereira e Luisa Cruz), fot. Paulo Cintra e Laura Castro Caldas.

entidades - texto e espectáculo - e para fazer surgir um novo olhar sobre o teatro, mais virado para o palco do que para o texto. E podia constatar-se que, virando costas a uma concepção do teatro centrada no texto dramático, as práticas artísticas modernas ou contemporâneas do teatro, conotadas por rupturas diversas do "novo" com o "antigo", poderiam ir até à total evacuação do palco da presença de qualquer texto (dramático escrito). Novos meios e novas linguagens permitiam introduzir a diversidade num domínio onde antes dominava um modelo único consagrado pela tradição.

Na verdade, a primazia do escrito ou do texto correspondia a uma espécie de cegueira ou, pelo menos, de miopia. A investigação desenvolvida em história cultural trouxe à luz do dia aspectos antes silenciados. Citemos nomeadamente os trabalhos de Raymond Chartier (2002) sobre a relação entre o escrito e o oral, a transmissão e a edição do teatro na época clássica, que lançam uma luz nova sobre as obras que chegaram até aos nossos dias: em Shakespeare ou em Molière, a prioridade ou a anterioridade do escrito sobre o trabalho dos actores ou o espectáculo não era a regra.

Por outro lado, a definição de "drama", referida acima, permite deduzir que, considerando-se o drama como sinónimo de teatro, a "dramatização" seria uma característica essencial (duma "concepção univoca") do "teatro" - ontem como hoje - que supõe o recurso a uma "peça escrita", portanto, a um "texto" entendido como materialização da acção no teatro.

Curiosamente, a definição do termo "dramatização" dada no dicionário de Patrice Pavis é duplamente útil neste ponto.

Numa acepção restrita, a dramatização é apresentada como uma prática de escrita assente, por um lado, numa transformação modal: "Adaptação de um texto (épico ou poético) em texto dramático ou num material para o palco"; mas é igualmente a expressão duma opção dramatúrgica (ou dramática) que corresponderia, na época contemporânea, a uma "vontade de não mais limitar o teatro a um texto dialogado escrito especificamente para o palco" (Pavis 1996: 104). Com efeito, a dramaturgia contemporânea, como é sabido, elabora-se muitas vezes pela via das formas mais diversas de manipulação de textos não teatrais, dando lugar a uma tipologia de textos que escapam às nomenclaturas estabelecidas, como a classificação por géneros, ou a regras e normas, de resto, tantas vezes contestadas no passado.

Assim, se a dramatização é, por definição, uma prática ao serviço do espectáculo teatral, ela remete-nos forçosamente para a questão do "texto" no teatro, reduzido aqui à sua condição mínima, enquanto matéria verbal "para" o palco, para que não venha a produzir-se falta "de/do" texto, mas dispensando agora a presença do modelo do texto dramático enquanto "peça escrita para o teatro", único filho legítimo que, não estando já ao serviço do espectáculo, se transforma numa espécie de presença-ausência.

3.

E se o texto, aparentemente expulso do palco, nunca tivesse deixado de estar presente? Sectores importantes da "vida teatral" (concebida aqui como campo ou "sistema") mostram que o texto dramático não perdeu vitalidade e até prosperou, apesar de aparentemente ter recuado ou ter sido impossibilitado de acesso ao palco e ao espectáculo teatral contemporâneo.

Sobre fundo de cartografia que permite a delimitação de diversas áreas de estudo daquilo que Pavis chama "esse estranho objecto de nome teatro" (1989: 97), a problemática do texto pode escapar a dicotomias consagradas, aparentemente inabaláveis (a mais célebre é sem dúvida a oposição entre texto/representação, dramático/performativo). Proponho, entre outras possibilidades, que nos detenhamos agora em duas 


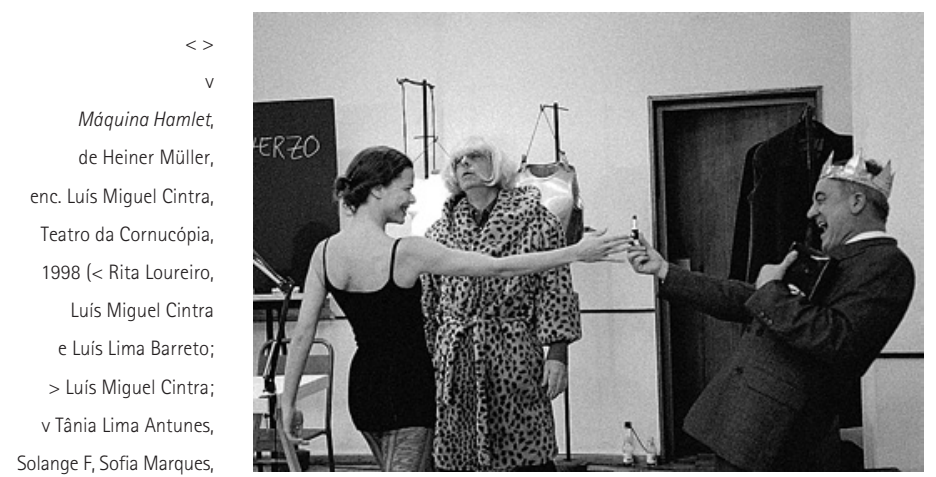

Luis Lucas

e Luis Miguel Cintra),

fot. Paulo Cintra

e Laura Castro Caldas.

abordagens do nosso assunto (que são também sugestões para trabalhos de investigação): uma é "dramatúrgica e cultural" (de que faz parte a tradução de teatro, por exemplo); a outra é "institucional ou sociológica" (compreende as políticas de repertório, as estratégias na edição, o ensino e a investigação). Também aqui o texto de teatro teve de ter em conta a sua nova relação com o palco e parece que retirou dai benefícios consideráveis.

$\mathrm{Na}$ abordagem "dramatúrgica e cultural" do teatro contemporâneo, o texto dramático surge simultaneamente como um factor de continuidade e de mudança, nomeadamente na prática generalizada da "reescrita" dos "textos". Os exemplos abundam.

A dramaturgia de Heiner Müller é, sem dúvida, a mais rica em procedimentos de transformação de textos pelo dramaturgo - do narrativo para o dramático - mas, em várias peças, passagens narrativas são mantidas como tal sob forma de fragmento, ombreando com os diálogos graças a um efeito de montagem que permite o confronto dos elementos entre si. Sem dramatização - no sentido que vimos acima -, Müller cria uma tensão entre o modo dramático dominante e o modo narrativo: o teatro é assim capaz de contar e comentar uma acção que não é mostrada. Um texto de tipo novo para uma renovação da arte do teatro em todas as suas dimensões.

A reescrita aposta muitas vezes numa prática do desvio que Pedro Eiras designa como um gesto anticultural (Eiras 2011: 58), inscrito na relação com a tradição, com vista a um novo uso do passado. A citação é outro procedimento recorrente: "[...] citar as obras da tradição retirando-Ihes o valor de culto, deixando-as imanentes, em processo de uso e nova hermenêutica" (Ibid.: 59).

Concebido como uma forma de reescrita pelos teóricos dos Estudos de Tradução, o texto traduzido para o teatro já não é um elemento secundário, um mal necessário. Actualmente, recusando o anonimato, a "tradução" do texto de teatro é assinada por tradutores, eles próprios autores ou ensaistas de nomeada, e muitas vezes publicada. Por outro lado, é considerada como um elemento determinante da relação intercultural, da relação do teatro com as outras culturas, outra caracteristica da cena contemporânea.

Numerosos trabalhos confirmam também a emergência de "novas dramaturgias" que surgem como "novas escritas", nascidas da crise do drama e da libertação do modelo canónico do texto, substituído pelo conceito de obra aberta, fluida, plural.

Liberto do preconceito sobre o valor literário do texto dramático, o texto escrito torna-se um elemento de corpo inteiro dos "géneros não-canónicos", muitas vezes de
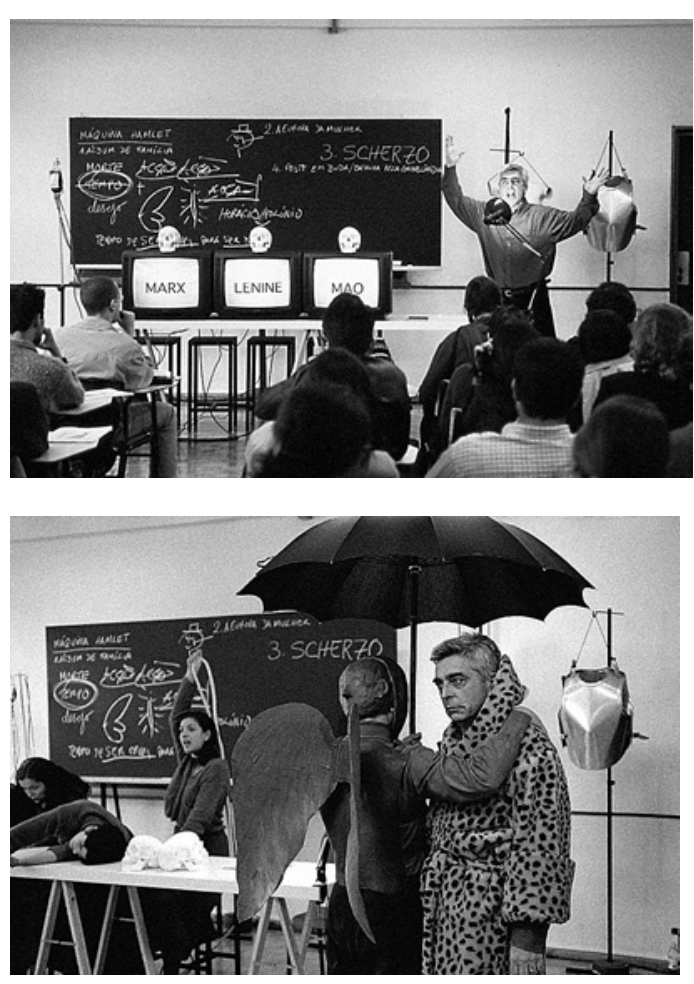

tradição oral ou inscritos na cultura popular, como é o caso do "teatro de marionetas", reconhecido como um dos sectores mais dinâmicos da cena contemporânea e marcado pela abertura do teatro em geral às outras artes. A ele são dedicadas obras onde o texto é objecto de uma atenção particular: Puppetry, de Penny Francis, fala de "uma dramaturgia moderna para a marioneta e para o teatro de objectos" (Francis 2012: 101). Não surpreende ninguém o facto de este colóquio acolher uma comunicação sobre esta prática artística.

$\mathrm{Na}$ "abordagem institucional do teatro", os trabalhos que estudam as políticas de repertório situam-nos no cruzamento de opções ao mesmo tempo dramatúrgicas e institucionais. 0 estudo da construção dos repertórios das companhias mostra sem surpresa que as peças clássicas nunca deixaram de ocupar um espaço importante nas políticas teatrais europeias desde os anos do pósguerra (Pavis 1990: 65-87). A sua apresentação ao público passa por um trabalho de releitura assente no pressuposto ideológico de uma actualidade das "obras" do passado (não dos "textos", distinção discutida por Barthes e citada por Pavis). Os encenadores recorrem agora a meios técnicos e artísticos novos, ao serviço das suas escolhas estéticas na fronteira do experimentalismo, e continuam a interpretar as obras e a dar-Ihes novas utilizações.

A "edição teatral" é outro campo revelador. À crise do texto de teatro e da escrita dramática, motivada, entre outras razões, por um divórcio real entre o palco e a dramaturgia dos autores, seguiram-se diversas mobilizações institucionais e a ajuda à edição de teatro é visivel nos catálogos dos editores, mais especializados hoje e que se dirigem a um público de leitores/espectadores (exemplo da revista Sinais de cena como informação sistemática). Os "ateliês de escrita" são também um fenómeno a ter em conta neste quadro.

No ensino e na investigação - nomeadamente em dramaturgia - pôde constatar-se uma renovação da 


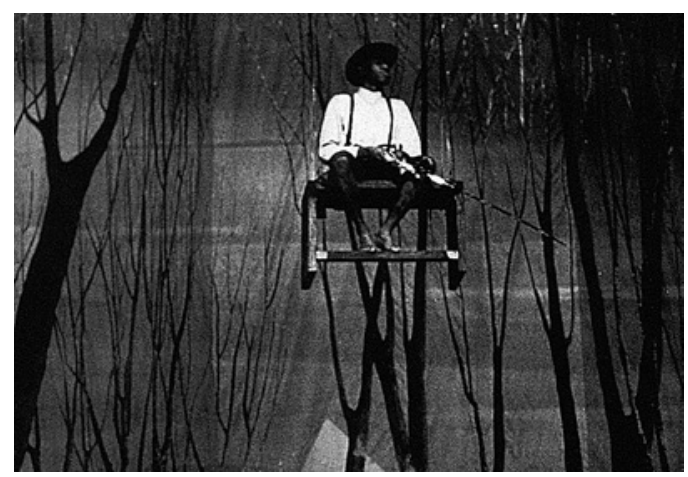

própria concepção da dramaturgia hoje. Depois de Lessing e Brecht, trabalhos recentes propõem que se considerem os textos na sua capacidade performativa (Turner / Berndt 2008), que se repense a dramaturgia (Sánchez 2011) na relação com as outras artes ou enquanto relação com o espectador contemporâneo, também ele de um tipo novo.

Concluirei com uma nota relativa ao quadro de referência temática que delimita e orienta as reflexões aqui expostas sobre o estatuto do texto no teatro contemporâneo: "0 teatro contemporâneo: Entre a dese a re-dramatização". 0 relevo dado à categoria temporal - o contemporâneo - constitui um quadro complexo, que extravasa aspectos meramente cronológicos. No final deste percurso, em que a presença hoje no teatro do objeto designado por texto é caracterizada por uma presença-ausência problemática, por uma reconfiguração da sua natureza e da sua função que reafirma a sua importância efetiva - ainda que relativizada no conjunto das linguagens postas ao serviço do espetáculo -, forçoso é interrogarmo-nos sobre a nossa relação com o contemporâneo: poderá ele excluir o antigo? 0 filósofo Giorgio Agamben aborda a questão com uma definição de Roland Barthes: "0 contemporâneo é inactual" (2008: 8), que resume nesses termos o pensamento singular de Nietzsche exposto nas suas Considerações inactuais. A definição pode surpreender pela sua aparente incongruência, mas revela-se particularmente estimulante aqui: o acesso à actualidade, ao contemporâneo, implica um certo desfasamento, uma discronia, percebida como uma distância que ajuda a ver, a saber ver, a obscuridade do contemporâneo, a não nos deixarmos cegar pela sua luz inacessivel. Propomos que tal percepção seja aqui tida em conta para servir de ponto de partida ao investigador que pretenda debruçar-se sobre um tema de tão grande complexidade como o que orienta este colóquio, em boa hora proposto para debate.

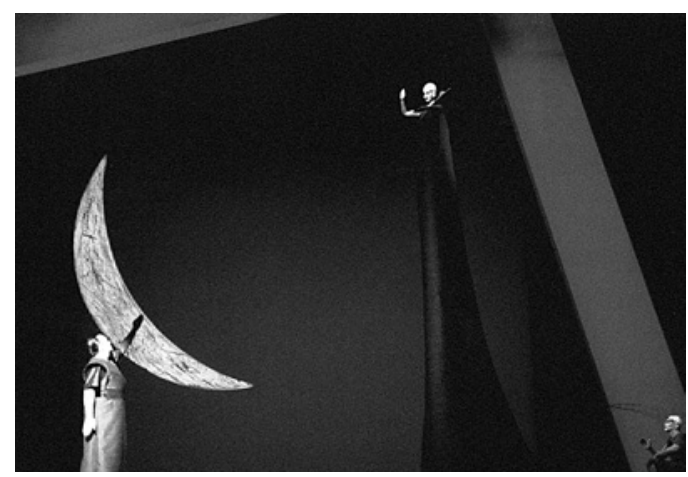

\section{Referências bibliográficas}

AGAMBEN, Giorgio (2008), Qu'est-ce que le contemporain?, Paris, Editions Payot \& Rivages.

ARON, Paul / SAINT-JACQUES, Denis / VIALA, Alain (dir.) (2002), Le dictionnaire du littéraire, Paris, PUF.

BIET, Christian / TRIAU, Christophe (2006), Qu'est-ce que le théâtre?, Paris, Éditions Gallimard, Folio Essais.

CHARTIER, Roger (2002), Do palco à página. Publicar teatro e ler romances na época moderna - séc. XVI-XVIII, Rio de Janeiro, Casa da Palavra. EIRAS, Pedro (2011), "O contemporâneo é aquele que responde pela tradição", in Um certo pudor tardio. Ensaio sobre os "poetas sem qualidades", Porto, ILCML/FLUP-Edições Afrontamento.

LIMON, Jerzy / ZUKOWSKA, Agniezka (2010), Theatrical Blends, Gdansk, slowo/obraz terytoria.

PAVIS, Patrice (1989), "Études théâtrales", in Théorie littéraire, sous la direction de Marc Angenot et al., Paris, Puf, pp. 95-107.

-- (1990), "L'héritage classique du théâtre postmoderne", in Le théâtre au croisement des cultures, Paris, José Corti, pp. 65-87.

-- (1996), Dictionnaire du théâtre, Paris, Dunod.

RIENDEAU, Pascal (2002), "Drame", in Le dictionnaire du littéraire, sous la direction de Paul Aron, Denis Saint-Jacques, Alain Viala, Paris, PUF, pp. 164-166.

SÁNCHEZ, José A. (2011), "Dramaturgia en el campo expandido", in Repensar la dramaturgia. Errancia Y transformación / Rethinking dramaturgy. Errancy and transformation, Manuel Bellisco et al. eds, Murcia, CENDEAC, pp. 19-37.

TURNER, Cathy / BERNDT, Synne K. (2008), Dramaturgy and Performance, Palgrave Macmillan.
The Deafman Glance, texto e enc. Robert Wilson, Brooklin Academy of Music Perfornance, New York, 1971 fot. Martin Bough.

Die Zauberflöte música de Wolfgang Amadeus Mozart, enc. Robert Wilson, Opéra Bastille, 1990, fot. Peter Perazio. 